\title{
Carga Horária Prática na Formação de Professores de Computação e Informática Educativa
}

\author{
Marcia Elena Jochims Kniphoff da Cruz ${ }^{13}$, Lucas Tadeu Hinterholz ${ }^{23}$, \\ Fernando Becker ${ }^{12}$ \\ ${ }^{1}$ Programa de Pós-graduação em Informática na Educação (PPGIE) - \\ Universidade Federal do Rio Grande do Sul (UFRGS) - Porto Alegre - RS - \\ Brasil \\ ${ }^{2}$ Programa de Pós-graduação em Educação (PPGEDU) - Universidade Federal \\ do Rio Grande do Sul (UFRGS) - Porto Alegre - RS - Brasil \\ ${ }^{3}$ Departamento de Computação - Curso de Licenciatura em Computação - \\ Universidade de Santa Cruz do Sul (UNISC) - Santa Cruz do Sul - RS - Brasil \\ \{marciakniphoff@gmail.com, lhinterholz@gmail.com, fbecker@gmail.com\}
}

\begin{abstract}
This paper presents the importance of the Hours Practice as Curricular Component (CHPCC) for teacher training in Computer Science and Educational Computing. The study is the partial result from research in course at the Graduate Program in Education - PPGIE, of Federal University of Rio Grande do Sul - UFRGS. It presents referential based on theoric approach of Genetic Epistemology and Cognitive Neuroscience. Concludes that the division of CHPCC conducted at the University of Santa Cruz do Sul UNISC includes legal aspects required by current law; and form students with necessary property to operate in Basic Education.
\end{abstract}

Resumo. Este artigo apresenta a importância da Carga Horária Prática como Componente Curricular (CHPCC) para formação do professor de Computação e Informática Educativa. $O$ estudo é resultado parcial de pesquisa em andamento no Programa de Pós-graduação em Informática na Educação - PPGIE, da Universidade Federal do Rio Grande do Sul-UFRGS. Apresenta referencial baseado na aproximação teórica entre Epistemologia Genética e Neurociência Cognitiva. Conclui que a divisão da CHPCC realizado na Universidade de Santa Cruz do Sul - UNISC contempla os aspectos legais exigidos pela legislação vigente e forma os estudantes com a devida propriedade para atuação na Educação Básica.

\section{Introdução}

A formação de professores de todos os níveis de ensino tem sido tema frequente de estudo no meio acadêmico brasileiro. Pesquisas investigam desde a estruturação dos cursos de Licenciatura até o impacto social provocado pelo aluno egresso. A maior quantidade de oferta de Licenciaturas ocorre, no País, através de cursos de Matemática, Ciências Biológicas, Química, Física, Letras, Línguas Estrangeiras, Educação Física, Sociologia, Filosofia, História e Pedagogia. Contudo, as demandas sociais que empregam tecnologias digitais para a educação e setores produtivos, acadêmicos e de 
V Congresso Brasileiro de Informática na Educação (CBIE 2016)

Anais do XXII Workshop de Informática na Escola (WIE 2016)

lazer, oportunizaram a oferta de um novo curso, a Licenciatura em Computação. O curso de Licenciatura em Computação no Brasil é reconhecido pelo Ministério da Educação (MEC) com várias denominações: "Licenciatura em Computação", "Licenciatura em Ciência da Computação", "Licenciatura em Informática", "Informática - Licenciatura", "Licenciatura Plena em Informática".

Este trabalho visa a aprofundar estudos sobre a Carga Horária Prática como Componente Curricular (CHPCC) e quais conteúdos deve abordar para implementar melhorias na formação do Licenciado em Computação. O licenciado em Computação tem a importante função de exercer docência em todas as modalidades da Educação Básica na área da Computação, valendo-se da Informática Educativa como apoio a todas as áreas do conhecimento. O currículo desse curso conta com disciplinas que integram as áreas de Computação, Educação, Matemática e, também, Psicologia, Sociologia, Filosofia, Língua Portuguesa e Língua Inglesa. Contam, ainda, com um grupo específico de disciplinas relacionadas à Informática na Educação denominadas: Informática Aplicada à Educação, Software Educacional, Multimídia Aplicada à Educação, Programação Aplicada à Educação, Informática na Educação a Distância, Informática e Aprendizagem, Inclusão Digital e Acessibilidade, Produção de Materiais Didáticos, Internet Aplicada à Educação e Tópicos Avançados em Informática Educativa.

Não são poucos os desafios da Licenciatura em Computação, no Brasil. Eles envolvem desde questões de identidade do curso e adequação pedagógica até aspectos mercadológicos e de reconhecimento de suas potencialidades (Castro e Vilarim, 2013, p. 1). Esse curso teve sua primeira oferta junto à Universidade de Brasília - UnB, em 1997. A segunda oferta ocorreu na Universidade de Santa Cruz do Sul - UNISC, em 1999. A partir de 2012, observou-se um crescimento exponencial na oferta de cursos de Licenciatura em Computação. São ofertados, hoje, cerca de 151 cursos em todo território nacional, conforme informações do Ministério da Educação - MEC. O crescimento na oferta desse curso demanda novas pesquisas na área da docência em Informática Educativa; até o momento poucas pesquisas foram feitas sobre tais cursos.

Alguns resultados começam a ser divulgados, como de Quim (2014) que desenvolveu pesquisa com alunos egressos de um curso de Licenciatura em Computação. Objetivou identificar os saberes pedagógicos dos licenciados em Computação e considera que a profissão do egresso do referido curso, enquanto carreira, ainda está por ser construída, pois são poucos os espaços legalmente instituídos para este profissional. Para ele, os alunos formados que deveriam trabalhar com uma concepção construtivista coerente com a formação obtida no curso, mostraram nas aulas por eles ministradas, reproduzirem modelos didático-pedagógicos tradicionais, com o uso de apresentações multimídia. Essa constatação remonta à leitura feita por Valente (1997), ainda no século passado, de que esses modelos refletem a capacitação dada aos professores para atuar em um sistema educacional que visa, somente, a transmissão de informação. Figueiredo, Nobre e Passos (2013) apontam desafios enfrentados por professores no uso de tecnologias educacionais que compreendem as dificuldades em explorar as potencialidades dos recursos disponíveis, falta de profissionais para a gestão e manutenção dos laboratórios, infraestrutura física e tecnológica dos laboratórios. 
Almeida e Carvalho (2012) levantam a necessidade de direcionar o conhecimento dos licenciados em computação para o desenvolvimento de práticas pedagógicas nas quais a demanda por educadores com habilidades inerentes à formação de professores e habilitação técnica necessária possa ser atendida. Estes estudos concluem que a formação do licenciado em computação ainda demanda de completude em pontos específicos.

É urgente a análise das condições em que é oferecido o curso de Licenciatura em Computação, sua estrutura curricular e a articulação de seus conteúdos para atendimento das áreas às quais responde. É essencial que esta reflexão inicie pela análise da oferta das disciplinas de Carga Horária Prática como Componente Curricular (CHPCC), segundo pareceres subsequentes à RESOLUÇÃO CNE/CP 2, de19 de Fevereiro de 2002. Posterior a essa Resolução foi lançada a RESOLUÇÃO No 2 , de $1^{\circ}$ de Julho de 2015, que mantém as quatrocentas horas.

A orientação fornecida pelo MEC sobre CHPCC é de que os cursos de Licenciatura garantam em seus projetos pedagógicos quatrocentas horas para cumprimento da mesma: "vivenciadas ao longo do curso". Além dessa carga horária, a Resolução ainda prevê: quatrocentas horas de estágio curricular supervisionado, que devem contar no total de três mil e duzentas horas.

A base teórica dos projetos pedagógicos dos cursos de Licenciatura deve considerar a epistemologia do professor. Segundo Becker (2012b), as concepções epistemológicas podem ser expressão do senso comum, empirismo ou apriorismo; ou expressar uma epistemologia crítica como a construtivista ou a relacional de base interacionista. A epistemologia crítica, como a construtivista ou a relacional de base interacionista articulada aos estudos de Epistemologia Genética de Piaget e Neurociência Cognitiva devem integrar os conteúdos da CHPCC das Licenciaturas em Computação. Cruz e Becker (2015) consideram que a CHPCC deva ser concebida para que os estudantes de Licenciatura em Computação tenham a oportunidade de tomar consciência dos principais aspectos da docência na área.

Considerando que a Licenciatura em Computação é um curso muito jovem, se comparado às demais licenciaturas, observa-se que apresenta dificuldades com o campo de atuação do profissional formado. Diante do exposto é necessário buscar respostas para três questões cruciais: 1 - Como a CHPCC vem sendo cumprida na estrutura curricular do curso de Licenciatura em Computação da Universidade de Santa Cruz do Sul - UNISC? 2 - Como vem sendo cumprida a CHPCC para dar conta da solicitação governamental mencionadas nas Resoluções supracitadas? 3 - O que o curso de Licenciatura em Computação da UNISC entende por "prática como componente curricular, vivenciada ao longo do curso"? Na tentativa de contribuir com a discussão, respondendo parte dessas questões, são apresentados dois indicadores compostos por: 1 - base teórica que envolve a aproximação entre estudos de Epistemologia Genética e Neurociência Cognitiva; 2 - organização, pela UNISC, da oferta da CHPCC em nove disciplinas específicas apresentadas na Tabela 1. 
V Congresso Brasileiro de Informática na Educação (CBIE 2016)

Anais do XXII Workshop de Informática na Escola (WIE 2016)

\section{Formação de professores: reflexões e conhecimentos imprescindíveis}

"A matéria prima do trabalho do professor é o conhecimento." (Becker. 2012, p. 84) Segundo o autor esse conhecimento prático constitui a matéria prima do conhecimento entendido como capacidade, mas ele, por si mesmo, não produz avanços. Este conhecimento prático é considerado por Piaget uma ação de primeiro grau. Ou seja, a montagem de um computador, por exemplo, não assegura que o estudante tenha avançado em conhecimento. $\mathrm{O}$ que interessa para a Epistemologia Genética é a ação de segundo grau; a ação sobre a ação anterior ou ação de primeiro grau. $\mathrm{O}$ mecanismo da abstração reflexionante, complementado pelo mecanismo da tomada de consciência, mostra que uma reflexão (ação de segundo grau) pressupõe um reflexionamento (ação de primeiro grau). Considera-se que a CHPCC deva ser concebida para que os estudantes de Licenciatura em Computação tenham a oportunidade de tomar consciência dos principais aspectos da docência na área; assim, faz-se necessário o estudo de Epistemologia Genética e Neurociência Cognitiva.

Estudos de Epistemologia Genética podem beneficiar-se dos achados das neurociências e neurocientistas podem fazer o mesmo com a Epistemologia Genética: "Se a Psicologia Genética nos diz o que os sujeitos humanos, por mérito dos cérebros de seus organismos, são capazes de fazer, as neurociências nos dizem como o cérebro produz emoções, mente e consciência e expressa comportamentos." (Becker. 2014, p. 62) Jean Piaget estudou a gênese das estruturas lógicas do pensamento, atribuindo à ação um significado preponderante na gênese do conhecimento:

A Epistemologia Genética elege a ação como cerne de sua explicação da gênese e do desenvolvimento do conhecimento - conhecimento estrutura, não apenas conteúdo. Mas ação compreendida como interação; isso é, como o processo que explica como a ação, iniciando pela assimilação, desdobra-se em acomodação que abre caminho para assimilações diferenciadas, em nível de melhor qualidade e maior amplitude em quantidade - equilibração majorante ou abstração reflexionante. (BECKER, 2014, p. 2)

O trabalho desenvolvido por Zaro et al (2012) prevê a integração dos achados de pesquisas das neurociências às necessidades de identificação das melhores formas de ensinar, para potencializar os resultados do aprendizado. Visa prover caráter científico à pesquisa educacional, estabelecendo um framework teórico e metodológico para que possam ser testadas as melhores práticas pedagógicas; sugere que a Neurociência possa também balizar o desenvolvimento e a pesquisa sobre o uso de produtos educacionais, em especial aqueles que se utilizam das tecnologias computadorizadas. Estes autores afirmam que a próxima geração de educadores obrigatoriamente precisará levar em conta o conhecimento gerado por pesquisas da Neurociência, da Ciência da Educação e Neuroeducação. A Neurociência Cognitiva superou o acreditado empirismo do final da década de 1950.

A Neurociência explora o cérebro como produtor da mente; vale-se de estudos da Psicologia Cognitiva e da atividade mental como uma questão de processamento de informações: "Nossas percepções, pensamentos e ações dependem de transformações 
internas [...].” (Gazzaniga, Richard e Mangun, 2006, p. 115) A informação é obtida pelos sentidos (abstração empírica), mas a habilidade humana de compreender a informação e escolher uma resposta depende de um processo complexo (abstração reflexionante) de atividades conjuntas. Damásio (2000) aprofunda estudos a respeito afirmando que os sentimentos são vitais e deles depende o conhecimento - os sentimentos são experiências mentais conscientes e não programas de ação para resolver problemas. A vida está além dos programas de ação, as experiências mentais - a consciência do que está se passando com o corpo - tem um papel de regulação da própria vida.

\section{A Carga Horária Prática como Componente Curricular}

A RESOLUÇÃO CNE/CP n. 02/2002 (p. 1) indica: “[...] 400 (quatrocentas) horas de prática como componente curricular, vivenciadas ao longo do curso." A CHPCC é apresentada com a mesma quantidade de horas na Resolução de 2015. Após o lançamento da Resolução de 2002, vários pareceres foram emitidos pelo MEC esclarecendo-a mais amplamente. O primeiro parecer analisado explica a CHPCC: “[...] importa à Instituição prever 400 horas de prática como componente curricular a se realizar desde o inicio do curso, o que pressupõe relacionamento próximo com o sistema de educação escolar." (MEC, Parecer de 13/5/2002, aprovado em 13/03/2002). Este esclarecimento reforça a necessidade da CHPCC contemplar a atuação do futuro professor junto à escola. Outro esclarecimento aponta para a prática como componente curricular afirmando que:

[...] o conjunto de atividades formativas que proporcionam experiências de aplicação de conhecimentos ou de desenvolvimento de procedimentos próprios ao exercício da docência. Por meio destas atividades, são colocados em uso, no âmbito do ensino, os conhecimentos, as competências e as habilidades adquiridos nas diversas atividades formativas que compõem o currículo do curso. As atividades caracterizadas como prática como componente curricular podem ser desenvolvidas como núcleo ou como parte de disciplinas ou de outras atividades formativas. Isto inclui as disciplinas de caráter prático relacionadas à formação pedagógica, mas não aquelas relacionadas aos fundamentos técnico-científicos correspondentes a uma determinada área do conhecimento. (MEC, Parecer de 13/05/2005, Despacho do Ministro em 9/5/2002.)

Destacam-se nesse esclarecimento duas fortes indicações sobre os conteúdos ou disciplinas de CHPCC: 1 - estarem relacionados à formação pedagógica; 2 - não deverem estar relacionados aos fundamentos técnico-científicos correspondentes a uma determinada área do conhecimento; ou seja, disciplinas dos Conteúdos Curriculares da Formação Tecnológica não devem empregar CHPCC.

Como exemplo, para atender ao disposto na legislação de formação de professores, o curso de Licenciatura em Computação da UNISC oferece nove disciplinas específicas que contemplam quatrocentas e vinte horas de CHPCC. A tabela a seguir apresenta as respectivas disciplinas e a distribuição da carga horária: 
V Congresso Brasileiro de Informática na Educação (CBIE 2016)

Anais do XXII Workshop de Informática na Escola (WIE 2016)

Tabela 1. Disciplinas com Carga Horária Prática como Componente Curricular

\begin{tabular}{|l|l|}
\hline \multicolumn{1}{|c|}{$\begin{array}{c}\text { Disciplinas com Carga Horária Prática } \\
\text { como Componente Curricular }\end{array}$} & Carga horária \\
\hline Instrumentalização para Programação Aplicada à Educação & 60 \\
\hline Informática Aplicada à Educação & 60 \\
\hline Instrumentalização para Inclusão Digital e Acessibilidade & 60 \\
\hline Didática & 60 \\
\hline Instrumentalização para Informática e Aprendizagem & 30 \\
\hline Práticas Articuladoras em Computação I & 30 \\
\hline Práticas Articuladoras em Computação II & 30 \\
\hline Práticas Articuladoras em Computação III & 30 \\
\hline Práticas Articuladoras em Computação IV & 60 \\
\hline Total & 420 \\
\hline
\end{tabular}

Fonte: (UNISC, 2013)

As disciplinas apresentadas na Tabela 1 foram elencadas para compor a CHPCC devido às suas especificidades que dizem respeito à atuação do licenciando em Computação, em sala de aula. Acredita-se que, através das quatrocentas horas da CHPCC, o curso da UNISC consegue oportunizar um ambiente propício à construção de conhecimento como capacidade ou competência cognitiva.

Os conteúdos, atualmente, abordados nas disciplinas de CHPCC dizem respeito a composição de referencial teórico para o estágio no Ensino Fundamental, Médio e Técnico-Profissionalizante; procedimentos para atuação em situações características do uso da Computação no cotidiano escolar, relação entre teorias de aprendizagem e do desenvolvimento humano, direitos humanos, educação pluricultural e pluriétnica, avaliação do processo de ensino-aprendizagem, relações étnico-raciais, história-cultura Afro-brasileira e Indígena e desenvolvimento de pesquisa e produção científica.

Reafirma-se que essas disciplinas devem oportunizar um ambiente de estudo favorável à adaptação dos estudantes de Licenciatura em Computação ao futuro campo de trabalho. O processo de adaptação cognitiva foi amplamente estudado por Piaget (1995) que enfatizou, em toda sua obra, a importância do agir em suas mais diferentes formas: comparar, operar, antecipar, tematizar, fazer abstração reflexionante pseudo-empírica ou refletida -, tomar consciência como componentes integrais do processo de construção do conhecimento.

\section{Construindo as respostas}

Este artigo apresentou um estudo sobre a CHPCC de Licenciatura em Computação; apresentou como a CHPCC é determinada na Resolução CNE/CP n. 02/2002 seguida da RESOLUÇÃO No 2, de $1^{\circ}$ de Julho de 2015; em esclarecimentos publicados pelo MEC e em pareceres. Apresentou especificidades de como a CHPCC é constituída no curso de Licenciatura em Computação da UNISC. Apresentou questões que exigem discussão rigorosa a ser promovida pelo corpo docente das universidades proponentes de cursos 
V Congresso Brasileiro de Informática na Educação (CBIE 2016)

Anais do XXII Workshop de Informática na Escola (WIE 2016)

de Licenciatura em Computação com base na Epistemologia Genética e Neurociência Cognitiva.

Em resposta à primeira questão: Como a CHPCC vem sendo cumprida na estrutura curricular do curso de Licenciatura em Computação? Conclui-se que o curso tem uma boa abordagem nos conteúdos tratados nas disciplinas de CHPCC, contudo deve formalizar estudos sobre Epistemologia Genética e Neurociência Cognitiva, pois estes vêm sendo trabalhados como estudos adjacentes. Esses conteúdos são básicos para a formação de professores, pois embasam a ação docente, a produção de materiais didáticos e ampliam os conhecimentos sobre como o ser humano aprende e constrói conhecimento. $\mathrm{O}$ curso de Licenciatura em Computação já oportuniza reflexão sobre a docência; nas disciplinas práticas são realizadas reuniões/seminários que debatem a didática e a práxis do ensino. (Cruz et al. 2007). Contudo, com a inserção dos conteúdos de Epistemologia Genética e Neurociência Cognitiva a reflexão será ampliada.

A segunda questão indaga se da forma como a CHPCC vem sendo cumprida, dá conta da solicitação governamental nas Resoluções supracitadas. Considera-se ideal a forma de oferta da CHPCC em disciplinas específicas como vem fazendo o curso de UNISC, conforme apresentado na Tabela 1. Conclui-se que, essa divisão da CHPCC contempla os aspectos legais exigidos pela legislação vigente e forma os estudantes com a devida propriedade para atuação na Educação Básica. São nove disciplinas que contemplam, satisfatoriamente a carga horária estabelecida pela legislação, inclusive ultrapassando em vinte horas.

A terceira questão exige mais reflexão: $O$ que o curso de Licenciatura em Computação da UNISC entende por "prática como componente curricular, vivenciadas ao longo do curso"? Essa resposta está em construção e para a reflexão deve-se retomar a seção 2 que exemplifica: a simples montagem de um computador não assegura que o estudante tenha avançado em conhecimento (Becker. 2012a). Logo, é necessário debruçar-se sobre o problema e buscar formas de aproveitar efetivamente o tempo das quatrocentas horas destinadas à CHPCC com ambiente favorável à construção do conhecimento. A Sociedade Brasileira de Computação - SBC está reformulando os currículos dos cursos de Licenciatura em Computação e deve considerar estudos da Epistemologia Genética e Neurociência cognitiva como conteúdos fundamentais.

Como proposição futura sugere-se que os professores das universidades que ofertam o curso de Licenciatura em Computação reúnam-se para discussões e aprofundamentos, considerando a base teórica apresentada. $\mathrm{O}$ aprofundamento deve visar o combate à toda forma de empirismo e apriorismo, na direção da construção de conhecimento por parte do futuro professor de Computação e Informática Educativa.

\section{Referências}

Almeida, Cristina C. e Carvalho, Luciano P. (2012) “A formação de professores no curso de Licenciatura em Computação: um relato das práticas educacionais de iniciação a docência". In: Anais do XVIII WIE. http://www.br-ie.org/pub/index.php/wie/article/view/2083/1850, Agosto. 
V Congresso Brasileiro de Informática na Educação (CBIE 2016)

Anais do XXII Workshop de Informática na Escola (WIE 2016)

Becker, Fernando. (2012a) "Epistemologia do professor de matemática". In: Vozes, Petrópolis, Brasil.

Becker, Fernando. (2012b) "Educação e construção do conhecimento". In: Penso, $2^{\mathrm{a}}$ Edição, Porto Alegre, Brasil.

Becker, Fernando. (2014) "Jean Piaget e António Damásio: Ensaio de aproximação”, In: Revista Eletrônica de Psicologia e Epistemologia Genéticas - Schème. v. 7, n. 1. Marília, Brasil.

http://www2.marilia.unesp.br/revistas/index.php/scheme/article/view/4276/3105, Abril.

Brasil. Ministério da Educação - MEC. (2015) "RESOLUÇÃO No 2, de $1^{\circ}$ de Julho de 2015".

http://portal.mec.gov.br/index.php?option=com_docman\&view $=$ download\&alias $=17$ 719-res-cne-cp-002-03072015\&category_slug=julho-2015-pdf\&Itemid=30192, Abril.

Brasil. Ministério da Educação - MEC. (2002) "RESOLUÇÃO CNE/CP n. 02/2002". In: http://portal.mec.gov.br/cne/arquivos/pdf/pces0015_05.pdf, Abril.

Brasil. Ministério da Educação - MEC. (2005) "Parecer Homologado". Despacho do Ministro, publicado no Diário Oficial da União de 13/05/2005, aprovado em 13/03/2002. In: http://portal.mec.gov.br/sesu/arquivos/pdf/CNECES109.pdf, Abril.

Brasil. Ministério da Educaçãon - MEC. (2016) "Instituições de Educação Superior e Cursos Cadastrados". In: http://emec.mec.gov.br/, Abril.

Castro, Cilmar S. Vilarim, Gilvan de O. (2013) "Licenciatura em Computação no cenário nacional: embates, institucionalização e o nascimento de um novo curso". In: Revista espaço acadêmico. Setembro, $\mathrm{n}^{\circ} 148$, http://www.periodicos.uem.br/ojs/index.php/EspacoAcademico/article/view/21635, Abril.

Cruz, Marcia, J. K. e Becker, Fernando. (2015) "Reflexões sobre a carga Horária Prática nos cursos de Licenciatura em Computação", In: Méritos, Adão et. al. (Organizadores). Prática Profissional na Educação Tecnológica concepções, experiências e dinâmicas investigativas. Instituto Federal de Educação, Ciência e Tecnologia Farroupilha, Campus Santo Antônio. Passo Fundo, Brasil.

Cruz et al. (2007) "Formação prática do licenciando em Computação para trabalho com Robótica Educativa". In: 2007. http://www.br-ie.org/pub/index.php/sbie/article/view/583/569, Maio.

Damásio, António. (2000) "O Mistério da Consciência: do corpo e das emoções à consciência de si”. In: Companhia das Letras, Tradução: Laura Teixeira Motta, São Paulo, Brasil. 
V Congresso Brasileiro de Informática na Educação (CBIE 2016)

Anais do XXII Workshop de Informática na Escola (WIE 2016)

Figueiredo, Gislaine L. R., Nobre, Isaura A. M. e Passos, Marize L. S. (2015) "Tecnologias Computacionais na Educação: Desafios na Prática Docente", In: CBIE-LACLO 2015, Anais do XXI Workshop de Informática na Escola (WIE 2015) Disponível em: http://www.br-ie.org/pub/index.php/wie/article/view/5006/3416, Agosto.

Gazzaniga, Michael S., Richard B. Ivry e Mangun, R. (2006) "Neurociência Cognitiva: a Biologia da mente". In: Artmed, Porto Alegre, Brasil.

Piaget, Jean. (1995) "Abstração reflexionante: relações lógico-aritméticas e ordem das relações espaciais". In: Artes Médicas, Porto Alegre, Brasil.

Quim, Osmar. (2014) "Licenciados em computação e saberes pedagógicos: cobranças de uma pedagogia da ação”. In: Repositório Digital LUME (UFRGS), Porto Alegre, Brasil, Tese (Doutorado em Educação) - Pós-graduação em Educação (PPGEDU) Universidade Federal do Rio Grande do Sul (UFRGS), In: http://www.lume.ufrgs.br/handle/10183/95761, Abril.

Unisc. (2013) "Projeto Pedagógico do Curso de Licenciatura em Computação". Universidade de Santa Cruz do Sul, Santa Cruz do Sul, Brasil.

Valente, José Armando e Almeida, Fernando José de. (1997) "Visão analítica da Informática na educação no Brasil: a questão da formação do professor”. In: Revista Brasileira de Informática na Educação, $\mathrm{n}^{\mathrm{o}} \quad 1$. http://www.br-ie.org/pub/index.php/rbie/article/view/2324/2083, Maio.

Zaro, M. A. et al. (2010) "Emergência da Neuroeducação: a hora e a vez da Neurociência para agregar valor à pesquisa educacional” In: Ciências \& Cognição, Vol 15 (1), pg. 199-210, http://www.cienciasecognicao.org, Abril. 